\title{
Neurocognition, social cognition and functional outcome in schizophrenia
}

\author{
losune Torio* \\ Alexandra Bagney ${ }^{*, * *}$ \\ Monica Dompablo*,** \\ Maria Jose Campillo* \\ Lorena Garcia-Fernandez ${ }^{\star * *}$ \\ Javier Rodriguez-Torresano*

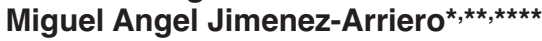

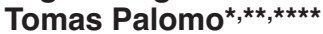 \\ Roberto Rodriguez-Jimenez ${ }^{\star, * *, \star \star * *}$ \\ * Department of Psychiatry, Instituto de \\ Investigación Hospital 12 de Octubre (i+12), \\ Madrid \\ ** Centro de Investigación Biomédica en \\ Red de Salud Mental (CIBERSAM) \\ *** Department of Psychiatry, Hospital de \\ San Juan. Universidad Miguel Hernández, \\ Alicante

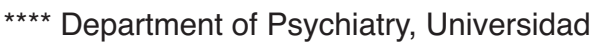 \\ Complutense de Madrid \\ SPAIN
}

\begin{abstract}
Background and Objectives: A relationship has been found between cognition and functioning in patients with schizophrenia. Our objective was to study the relationship between the cognitive domains assessed by the MATRICS Consensus Cognitive Battery (MCCB), and functioning as evaluated using the functioning subscale of the Global Assessment of Functioning scale (GAF-f).

Methods: A sample of 83 clinically stable outpatients diagnosed with schizophrenia according to DSM-IV criteria were assessed using the MCCB and the GAF-f. Pearson correlations and stepwise linear regression analyses were performed.

Results: Correlation analysis between the GAF-f and the cognitive domains of the MCCB showed a significant relationship between functioning and all of the cognitive domains. Regression yielded a statistically significant model $\left(\mathrm{F}_{2,74}=20.4, \mathrm{p}<0.001\right)$ in which functioning was related to Speed of processing (standardized $\beta=0.369, p=0.001$ ) and to Social cognition (standardized $\beta=0.325, \mathrm{p}=0.003$ ). Together, these two variables explained $33.8 \%$ of the variance of functioning.

Conclusions: Both speed of processing and social cognition have an important association with functioning in patients with schizophrenia.
\end{abstract}




\section{Introduction}

Cognitive deficits have been considered to be a core symptom of schizophrenia from the earliest descriptions of the disorder ${ }^{1,2}$. Cognitive impairments have been found in patients suffering from years of illness ${ }^{3}$, but also in those with a first psychotic episode ${ }^{4}$, in clinically remitted ${ }^{5,6}$ and in neurolepticnaïve patients ${ }^{7}$, in subjects at high risk for developing psychosis ${ }^{8,9}$, and even in healthy siblings of patients with schizophrenia ${ }^{10}$. The cognitive performance of schizophrenia patients is one to two standard deviations below that of healthy subjects ${ }^{11-13}$.

Schizophrenia patients also exhibit important deficits in their personal and social functioning leading to difficulties in different areas such as everyday activities, interpersonal relationships, or academic and work performance ${ }^{14-17}$. Cognitive impairment is considered to be one of the main factors influencing functioning in schizophrenia, and many studies have found associations between cognitive performance and functioning in patients with this disorder ${ }^{18,19}$.

Regarding the different cognitive processes, neurocognition has often been separated from social cognition. Neurocognition refers to the processes of linking and appraising information, and includes cognitive domains that have traditionally been referred to as "cognitive" in the literature, such as speed of processing, working memory, attention, memory, or executive functions ${ }^{20}$. Social cognition refers to the mental operations underlying social interactions such as perception, interpretation, and generation of responses to the intentions, dispositions, and behaviors of others $^{21-25}$.

The relationship between neurocognition and functioning has been quantified as moderate in different studies. Thus, between $20 \%$ and $60 \%$ of the variance of functioning in schizophrenia patients could be explained by neurocognitive performance, which is a better predictor of functioning than the positive symptoms of the disorder ${ }^{26-29}$.

In addition to neurocognitive deficits, patients with schizophrenia have been shown to exhibit deficits in social cognition ${ }^{30-33}$. Many studies in the last years have also associated social cognition with functioning, so that social cognitive performance would explain an additional proportion of the variance of functioning that is not explained by neurocognition $^{16,34-42}$. Some studies have even found that social cognition could be a better predictor of functioning than neurocognition itself ${ }^{29,43}$.

One of the problems when comparing the results of different studies on cognition in schizophrenia was the lack of consensus regarding which cognitive domains to evaluate and what instruments to use for their assessment. This obstacle, which also hindered the development of interventions designed to improve cognition, led the Measurement and Treatment Research to Improve Cognition in Schizophrenia (MATRICS) initiative of the U.S. National Institute of Mental Health (NIMH) to develop a consensus battery for the assessment of cognitive functioning: the MATRICS Consensus Cognitive Battery (MCCB). The battery is composed of 10 tests $^{44}$ which evaluate the 7 cognitive domains (6 neurocognitive domains, plus a seventh social cognition domain) that are impaired in schizophrenia $^{20}$, and the process of standardization and obtaining normative data was carried out in the U.S. by Kern et al. ${ }^{45}$. Our group carried out the co-norming and standardization of the MCCB in Spain in collaboration with developers of the battery ${ }^{46}$.

To our knowledge, there are no studies in our country assessing the relationship between cognition and functioning in schizophrenia using the MCCB (with the translation 
and community norms for Spain) and the functioning subscale of the Global Assessment of Functioning (GAF-f $)^{47}$. The objective of the present study was to analyse the relationship between functioning as assessed using the GAF-f and the different cognitive domains evaluated by the MCCB in a sample of Spanish patients with schizophrenia.

\section{Methods}

\section{Sample}

The present cross-sectional study was carried out in 83 clinically stable outpatients aged 18 to 60 years with a confirmed DSM-
IV diagnosis of schizophrenia ${ }^{48}$ as diagnosed with the Structured Clinical Interview for DSM-IV Axis I Disorders (SCID-I) ${ }^{49}$. The patients were recruited at Hospital Universitario 12 de Octubre (Madrid, Spain). All participants were on antipsychotic treatment and had been clinically stable (no changes in treatment, no significant psychopathological changes, no hospital admissions) for at least 3 months before inclusion. Patients with substance dependence in the past 6 months, substance abuse in the past month, neurological disease or head injury were excluded from the study. Written informed consent was obtained from all participants prior to their inclusion in the study. The demographic and clinical characteristics of the sample are presented in Table 1.

Table 1

Demographic and clinical characteristics and MCCB cognitive domain scores for the sample. Results are displayed as Mean (Standard deviation) or $N(\%)$ as appropriate.

\begin{tabular}{ll} 
Age (years) & $41.2(8.3)$ \\
\hline Age at onset of illness (years) & $25.0(6.8)$ \\
\hline $\begin{array}{l}\text { Gender } \\
\text { Male }\end{array}$ & $56(67.5 \%)$ \\
$\quad$ Female & $27(32.5 \%)$ \\
\hline Educational level (years) & $10.8(3.8)$ \\
\hline Antipsychotic & $63(78.8 \%)$ \\
$\quad$ Second generation & $9(10.8 \%)$ \\
$\quad$ First generation & $8(9.6 \%)$ \\
\hline Combined & $56.5(13.5)$ \\
\hline GAF - fa score & $37.4(13.0)$ \\
\hline Speed of Processing T - score & $39.8(10.1)$ \\
\hline Attention/Vigilance T - score & $38.3(13.6)$ \\
\hline Working Memory T - score & $33.6(15.6)$ \\
\hline Verbal Learning T - score & $36.0(14.5)$ \\
\hline Visual Learning T - score & $40.8(12.4)$ \\
\hline Reasoning and Problem Solving T - score & $39.5(13.6)$ \\
\hline
\end{tabular}

${ }^{a}$ Global Assessment of Functioning, functioning subscale. 


\section{Instruments}

The Global Assessment of Functioning $(G A F)$ scale

The GAF scale $\mathrm{e}^{50}$ is a global measure of the patient's status. It assesses the severity of mental illness through the individual's symptoms and functioning on a social and occupational level. Based on a revision of Endicott's Global Assessment Scale (GAS) ${ }^{51}$, the GAF was published in 1987 and became Axis V for DSM-III-R, DSM-IV and DSM-IV$\mathrm{TR}^{48,50,52}$. The score for both symptoms and functioning ranges from 1 to 100, and is divided into 10 intervals of 10 points. Each of these intervals has a description of the level of symptoms and functioning that are appropriate for this score. At the two extremes, the 1 to 10 interval includes the most severely ill subjects (persistent danger of severely hurting self or others, or persistent inability to maintain minimal personal hygiene, or serious suicidal act with clear expectation of death), whereas the 91 to 100 interval represents the healthiest individuals (superior functioning in a wide range of activities, life's problems never seem to get out of hand, is sought out by others because of his or her many positive qualities; no symptoms). After publication of the GAF, the GAF-Split version ${ }^{53,54}$ was described, with separate scales for symptoms (GAF-s) and functioning (GAF-f), and whose validity has later been established ${ }^{55}$. Because the goal of our study was to evaluate functioning, only the GAF-f subscale was used.

The MATRICS Consensus Cognitive Battery $(M C C B)$

The MATRICS Consensus Cognitive Battery (MCCB) was used for the cognitive assessment of patients. This battery is composed of 6 neurocognitive domains, plus a seventh social cognition domain. These seven domains are assessed using 10 neuropsychological tests, as follows: 1) Speed of Processing (Trail Making Test, Part A; Brief Assessment of Cognition in Schizophrenia, symbol coding subtest; Category fluency test, animal naming); 2) Attention/Vigilance (Continuous Performance Test, Identical Pairs version); 3) Working Memory (Wechsler Memory Scale, 3rd ed., spatial span subtest; Letter - Number Span test); 4) Verbal Learning (Hopkins Verbal Learning Test - Revised); 5) Visual Learning (Brief Visuospatial Memory Test - Revised); 6) Reasoning and Problem Solving (Neuropsychological Assessment Battery, mazes subtest); and 7) Social Cognition (Mayer - Salovey - Caruso Emotional Intelligence Test, managing emotions branch $)^{44}$. The tests are administered in a specified order, and take approximately $65 \mathrm{~min}$ utes. Participants' scores for each cognitive domain were converted into T-scores using Spanish normative data, based on the results of the MCCB co-norming and standardization process that was carried out by our group in Spanish population ${ }^{(46)}$.

\section{Statistical analysis}

The mean and standard deviation (SD) were used to describe continuous variables, while percentages were used for categorical variables. Pearson's correlations were first performed between the GAF-f score and the different MCCB cognitive domains. This was followed by stepwise linear regression analyses with the GAF-f score as the dependent variable, and the cognitive domains scores that were found to be significant in the correlation analysis as the independent variables. P-values of $<0.05$ were considered statistically significant. Data was managed and analysed using SPSS version 20. 


\section{Results}

Table 1 shows the GAF-f and MCCB cognitive scores for the sample. The mean GAFf score was $56.5(\mathrm{SD}=13.5)$. Among the different cognitive domains, the highest scores were obtained for Reasoning and problem solving (mean $=40.8, \mathrm{SD}=12.4$ ) and Attention/vigilance $($ mean $=39.8, \mathrm{SD}=10.1)$. The lowest scores corresponded to the Verbal learning (mean $=33.6, \mathrm{SD}=15.6)$ and Visual learning $($ mean $=35.9, \mathrm{SD}=14.5)$ domains.
The first step of the data analysis was a correlation between the GAF-f and MCCB cognitive domain scores. As shown in Table 2 , all correlations were statistically significant. Pearson's correlation coefficients ranged from $0.273(\mathrm{p}=0.014)$ for Attention/vigilance, to $0.523(\mathrm{p}<0.001)$ for Speed of processing.

Finally, a linear regression analysis was performed, with the GAF-f score as the dependent variable and the different MCCB cognitive domain scores as the independent

Table 2

Pearson's correlations between the GAF-f and the MCCB cognitive scores.

\begin{tabular}{ccccccc}
$\begin{array}{c}\text { Speed of } \\
\text { processing }\end{array}$ & $\begin{array}{c}\text { Attention/ } \\
\text { Vigilance }\end{array}$ & $\begin{array}{c}\text { Working } \\
\text { Memory }\end{array}$ & $\begin{array}{c}\text { Verbal } \\
\text { Learning }\end{array}$ & $\begin{array}{c}\text { Visual } \\
\text { Learning }\end{array}$ & $\begin{array}{c}\text { Reasoning } \\
\text { and } \\
\text { Problem } \\
\text { Solving }\end{array}$ & $\begin{array}{c}\text { Social } \\
\text { Cognition }\end{array}$ \\
\hline $\mathrm{r}=0.523$ & $\mathrm{r}=0.273$ & $\mathrm{r}=0.359$ & $\mathrm{r}=0.368$ & $\mathrm{r}=0.470$ & $\mathrm{r}=0.460$ & $\mathrm{r}=0.499$ \\
$\mathrm{p}<0.001$ & $\mathrm{p}=0.014$ & $\mathrm{p}=0.001$ & $\mathrm{p}=0.001$ & $\mathrm{p}<0.001$ & $\mathrm{p}<0.001$ & $\mathrm{p}<0.001$ \\
\hline
\end{tabular}

a Global Assessment of Functioning, functioning subscale.

variables. Using the stepwise method, a significant model emerged $\left(\mathrm{F}_{2,74}=20.4, \mathrm{p}<0.001\right)$. As shown in table 3, better functioning was related to higher scores in Speed of processing (standardized $\beta=0.369, \mathrm{p}=0.001$ ) and in Social cognition (standardized $\beta=0.325$, $\mathrm{p}=0.003$ ). Calculation of corrected $\mathrm{R}^{2}$ showed that these two variables together explained $33.8 \%$ of the variance in functioning.

\section{Table 3}

Stepwise linear regression analysis with the GAF-f scores as the dependent variable, and the MCCB cognitive domain T-scores as the independent variables.

\begin{tabular}{llccc} 
Dependent variable & Independent variables & Standardized $\beta$ & $t$ & $\mathrm{p}$ \\
\hline GAF-f $^{\text {a }}$ & Speed of processing & 0.369 & 3.486 & 0.001 \\
& Social cognition & 0.325 & 3.068 & 0.003 \\
\hline
\end{tabular}

${ }^{a}$ Global Assessment of Functioning, functioning subscale. 


\section{Discussion}

Schizophrenia patients in this study had a mean level of functioning as assessed by the GAF-f indicating moderate difficulties in social, occupational, or school functioning. These results are comparable to the scores found in other studies that have used the GAF to assess functioning in schizophrenia patients $^{56,57}$. As has been previously described in schizophrenia ${ }^{12,13}$ the mean scores of our patient sample for all MCCB cognitive domains were between one and two standard deviations below the population mean $(\mathrm{T}=50)$.

The main finding of the present study was that although all of the MCCB cognitive domains showed a statistically significant correlation with functioning, when the regression analysis was performed only Speed of processing and Social cognition were significantly related to functioning.

Speed of processing scores for our patient sample were below the population mean, as has been described in other schizophrenia studies $^{44,58-61}$. In fact, impaired speed of processing has been found not only in patients with schizophrenia, but also in subjects at high risk for developing psychosis ${ }^{62,63}$, in patients with first-episode schizophrenia spectrum disorders ${ }^{64}$, and in healthy relatives of schizophrenia patients ${ }^{65,66}$. The relationship between speed of processing and functioning found in the present study has also been described by other authors. Thus, speed of processing deficits have been associated with impairments in different domains of functional outcome such as global psychosocial functioning ${ }^{60,67}$, community functioning ${ }^{68}$, daily problem solving skills ${ }^{69}$, job tenure ${ }^{70}$, social skills ${ }^{71}$, or independent living skills ${ }^{72}$.

It is noteworthy that the remaining cognitive domains were not included in the regression model. Speed of processing has been defined as a basic cognitive process which allows processing information and performing simple cognitive tasks fluently and automatically. Over two decades ago, Salthouse ${ }^{73}$ proposed that a decrease in the speed of processing led to impairments in more complex cognitive processes. Later, different authors have described processing speed impairments as underlying other cognitive deficits in schizophrenia ${ }^{74-77}$ and in first-episode schizophrenia spectrum disorders ${ }^{78}$. This could explain why, despite the fact that all of the neurocognitive domains correlated significantly with functioning, only Speed of processing made it to the regression model. This highlights the relevance of this cognitive domain with regards to functioning in schizophrenia patients, and its special consideration when developing therapeutic strategies that target cognitive symptoms in these patients.

The other cognitive domain that appears in the regression model is Social cognition. As has been described in previous studies, there is a relationship between social cognition and functioning in schizophrenia ${ }^{15,33-41,79}$. For example, a review published by Couture et $a l .{ }^{15}$ established an association between community functioning and different domains of social cognition (social perception, emotion perception and Theory of Mind). It has been even suggested that social cognition may be more relevant for functional outcome than neurocognition ${ }^{28,34,42}$. Thus, the Fett $e t$ $a l .{ }^{28}$ meta-analysis studying the relationship of neurocognition and social cognition with different functional outcome domains in schizophrenia found that social cognition was more related to community functioning than neurocognition. However, our regression model yielded very similar standardized betas for Speed of processing and for Social cognition (in fact, the standardized beta for Social cognition was found to be slightly lower than for Speed of processing). This discrepancy with the studies that found social cognition to 
be more related to community functioning than neurocognition could be due to different methodological factors, especially the fact that the social cognition construct includes several domains, and the existence of different instruments for their assessment. In this respect, although social cognition has been extensively studied in healthy individuals, only a subset of social cognition domains have been studied in patients with schizophrenia ${ }^{80}$. Thus, the MATRICS initiative has proposed that for research in this area, social cognition may be divided into five partially overlapping domains: Theory of Mind, social perception, social knowledge, attributional bias and emotional processing. When predicting functional outcome, it could be that social cognition may have a greater impact than neurocognition if certain domains of the two constructs are considered. For example, in the abovementioned study, Fett et al. ${ }^{28}$ concluded that social cognition was more related than neurocognition to functional outcome and that this was specifically due to the association between the Theory of Mind domain of social cognition and the Community Functioning domain of functional outcome. Thus, the prevailing role of social cognition over neurocognition when predicting functional outcome should be generalised with caution to the remaining domains of social cognition, or to other aspects of functioning ${ }^{15}$. The need for valid and reliable consensus instruments for the assessment of both social cognition and functioning is evident.

In this respect, a possible limitation of our study is the selection of instruments. The MCCB only assesses one aspect of social cognition (managing emotions, which is a part of emotional processing). Although the use of other instruments was considered, we preferred to use a consensus instrument that is used worldwide to assess neurocognition and social cognition, and has been translated and validated in our country. Similarly, al- though there are other instruments designed to assess functioning, we chose the GAF-f due to its extensive and ample clinical use.

To conclude, this is the first study in Spain with results that support the existence of a relationship between functioning and cognition in patients with schizophrenia using the MCCB. Functioning is mainly related to speed of processing and to social cognition. Given the relevance of functional recovery in these patients, further research is required to improve our knowledge of the factors that may be associated with functional outcome in schizophrenia.

\section{Role of the funding source}

This research was supported in part by grant PI080514 (Fondo de Investigaciones Sanitarias, FIS), by Madrid's Regional Government (S2010/BMD-2422 AGES) and European Union Structural Funds, and by the Centro de Investigación Biomédica en Red de Salud Mental (CIBERSAM) of the Instituto de Salud Carlos III.

\section{Contributors}

IT, TP and RRJ designed the study and wrote the protocol. AB, MD, MJC and LG managed the literature searches and analyses. MD, MJC, LG and JRT selected the sample, evaluated patients and contributed in some aspects of the study design and in the interpretation of results. IT, MAJA, TP and RRJ undertook the statistical analysis. IT, AB and RRJ wrote the first draft of the manuscript. All authors contributed to and have approved the final manuscript. 


\section{Conflict of interest}

The authors report no biomedical financial interests or potential conflicts of interest.

\section{Acknowledgement}

We thank the Instituto de Investigación Hospital 12 de Octubre, the Madrid Regional Government and European Union Structural Funds, and the Centro de Investigación Biomédica en Red de Salud Mental (CIBERSAM) of the Instituto de Salud Carlos III.

\section{References}

1. Kraepelin E. Dementia Praecox and Paraphrenia. Edinburgh, Scotland: E. \& S. Livingstone. 1919.

2. Bleuler E. Dementia praecox or the group of schizophrenias. New York: International Universities Press. 1950.

3. Reichenberg A. The assessment of neuropsychological functioning in schizophrenia. Dialogues Clin Neurosci. 2010; 12: 383-92.

4. Addington J, Brooks BL, Addington D. Cognitive functioning in first episode psychosis: Initial presentation. Schizophr Res. 2003; 44: 47-56.

5. Asarnow RF, MacCrimmon DJ. Residual performance deficit in clinically remitted schizophrenics: A marker of schizophrenia? J Abnorm Psychol. 1978; 87: 597-608.

6. Nuechterlein KH, Dawson ME, Gitlin M, Ventura J, Goldstein MJ, Snyder KS, et al. Developmental processes in schizophrenic disorders: Longitudinal studies of vulnerability and stress. Schizophr Bull. 1992; 18: 387-425.

7. Torrey EF. Studies of individuals with schizophrenia never treated with antipsychotic medication: A review. Schizophr Res. 2002; 58: 101-15.

8. Erlenmeyer-Kimling L, Cornblatt B. Attentional measures in a study of children at high-risk for schizophrenia. $\mathrm{J}$ Psychiatr Res. 1978; 14: 93-8.

9. Cornblatt BA, Lenzenweger MF, Dworkin RH, Erlenmeyer-Kimling L. Childhood attentional dysfunctions pre- dict social deficits in unaffected adults at risk for schizophrenia. Br J Psychiatry Suppl. 1992; 18: 59-64.

10. Kuha A, Tuulio-Henriksson A, Eerola M, Perälä J, Suvisaari J, Partonen T, et al. Impaired executive performance in healthy siblings of schizophrenia patients in a populationbased study. Schizophr Res. 2007; 92: 142-50.

11. Heinrichs RW, Zakzanis KK. Neurocognitive deficit in schizophrenia: A quantitative review of the evidence. Neuropsychology. 1998; 12: 426-45.

12. Bilder RM, Goldman RS, Robinson D, Reiter G, Bell L, Bates JA, et al. Neuropsychology of first-episode schizophrenia: Initial characterization and clinical correlates. Am. J. Psychiatry. 2000; 157: 549-59.

13. Keefe RS, Fenton WS. How should DSM-V criteria for schizophrenia include cognitive impairment? Schizophr Bull. 2007; 33: 912-20.

14. Bellack AS, Green MF, Cook JA, Fenton W, Harvey PD, Heaton RK, et al. Assessment of community functioning in people with schizophrenia and other severe mental illnesses: A white paper based on an NIMH-sponsored workshop. Schizophr Bull. 2007; 33: 805-22.

15. Couture SM, Penn DL, Roberts DL. The functional significance of social cognition in schizophrenia: A review. Schizophr Bull. 2006; 32 (Suppl 1): S44-63.

16. Flashman LA, Green MF. Review of cognition and brain structure in schizophrenia: Profiles, longitudinal course, and effects of treatment. Psychiatr Clin North Am. 2004; 27: $1-18$.

17. Harvey PD, Green MF, Keefe RS, Velligan DI. Cognitive functioning in schizophrenia: A consensus statement on its role in the definition and evaluation of effective treatments for the illness. J Clin Psychiatry. 2004; 65: 361-72.

18. Green MF. What are the functional consequences of neurocognitive deficits in schizophrenia? Am J Psychiatry. 1996; 153: 321-30.

19. Bowie CR, Leung WW, Reichenberg A, McClure MM, Patterson TL, Heaton RK, et al. Predicting schizophrenia patients' real-world behavior with specific neuropsychological and functional capacity measures. Biol Psychiatry. 2008; 63: 505-11.

20. Nuechterlein KH, Barch DM, Gold JM, Goldberg TE, Green MF, Heaton RK, et al. Identification of separable cognitive factors in schizophrenia. Schizophr Res. 2004; 72: 29-39.

21. Green MF, Penn DL, Bentall R, Carpenter WT, Gaebel W, Ruben GC, et al. Social cognition in schizophrenia: An NIMH workshop on definitions, assessment, and research opportunities. Schizophr Bull. 2008; 34: 1211-20. 
22. Ostrom TM. The sovereignty of social cognition. In: Wyer RS, Srull TK, eds. Handbook of Social Cognition. Hillsdale, NJ: Erlbaum 1984; 1: 1-37.

23. Brothers L. The neural basis of primate social communication. Motiv Emot. 1990; 14: 81-91.

24. Kunda Z. Social Cognition: Making Sense of People. Cambridge, MA: MIT Press. 1999.

25. Fiske ST, Taylor SE. Social Cognition. 2nd ed. New York, NY: McGraw-Hill Book Company. 1991.

26. Velligan DI, Mahurin RK, Diamond PL, Hazleton BC, Eckert SL, Miller AL. The functional significance of symptomatology and cognitive function in schizophrenia. Schizophr Res. 1997; 25: 21-31.

27. Green MF, Kern RS, Braff DL, Mintz J. Neurocognitive deficits and functional outcome in schizophrenia: Are we measuring the "right stuff'? 2000; 26: 119-36.

28. Green MF, Kern RS, Heaton RK. Longitudinal studies of cognition and functional outcome in schizophrenia: Implications for MATRICS. Schizophr Res. 2004; 72: 41-51.

29. Fett AK, Viechtbauer W, Dominguez MD, Penn DL, van Os J, Krabbendam L. The relationship between neurocognition and social cognition with functional outcomes in schizophrenia: A meta-analysis. Neurosci Biobehav Rev. 2011; 35: 573-88.

30. Van't Wout M, Aleman A, Bermond B, Kahn R.S. No words for feelings: Alexithymia in schizophrenia patients and first-degree relatives. Compr Psychiatry. 2007; 48: 27-33.

31. Pijnenborg GHM, Withaar FK, Bosch van den RJ, Brouwer WH. Impaired perception of negative emocitional prosody. Clin Neuropsychol. 2007; 52: 236-40.

32. Horan WP, Kern RS, Shokat-Fadai K, Sergi MJ, Wynn JK, Green MF. Social cognitive skills training in schizophrenia: An initial efficacy study of stabilized outpatients. Schizophr Res. 2009; 107: 47-54.

33. Sparks A, McDonald S, Lino B, O’Donnell M, Green MJ. Social cognition, empathy and functional outcome in schizophrenia. Schizphr Res. 2010; 122: 172-8.

34. Addington J, Saeedi H, Addington D. The course of cognitive functioning in first episode psychosis: Changes over time and impact on outcome. Schizophr Res. 2005; 78: $35-43$.

35. Pinkham AE, Penn DL. Neurocognitive and social cognitive predictors of interpersonal skill in schizophrenia. Psychiatry Res. 2006; 143: 167-78.

36. van Hooren S, Versmissen D, Janssen I, Myin-Germeys I, à Campo J, Mengelers R, et al. Social cognition and neurocognition as independent domains in psychosis. Schizophr Res. 2008; 103 (1-3): 257-65.
37. Mancuso F, Horan WP, Kern RS, Green MF. Social cognition in psychosis: Multidimensional structure, clinical correlates, and relationship with functional outcome. Schizophr Res. 2011; 235: 143-51.

38. Brekke J, Kay DD, Lee KS, Green MF. Biosocial pathways to functional outcome in schizophrenia. Schizophr Res. 2005; 80: 213-25.

39. Brüne M. Emotion recognition, "theory of mind", and social behaviour in schizophrenia. Psychiatry Res. 2005; 133: $135-47$.

40. Penn DL, Spaulding W, Reed D, Sullivan M. The relationship of social cognition to ward behavior in chronic schizophrenia. Schizophr Res. 1996; 20: 327-35.

41. Pinkham AE, Penn DL. Neurocognitive and social cognitive predictors of interpersonal skill in schizophrenia. Psychiatry Res. 2006; 143: 167-78.

42. Waldheter EJ, Jones NT, Johnson ER, Penn DL. Utility of social cognition and insight in the prediction of inpatient violence among individuals with a severe mental illness. J Nerv Ment Dis. 2005; 193: 609-18.

43. Pijnenborg GH, Withaar FK, Evans JJ, van den Bosch RJ, Timmerman ME, Brouwer WH. The predictive value of measures of social cognition for community functioning in schizophrenia: Implications for neuropsychological assessment. J Int Neuropsychol Soc. 2009; 15: 239-47.

44. Nuechterlein KH, Green MF, Kern RS, Baade LE, Barch D.M, Cohen JD, et al. The MATRICS Consensus Cognitive Battery, part 1: Test selection, reliability, and validity. Am J Psychiatry. 2008; 165: 203-13.

45. Kern RS, Nuechterlein KH, Green MF, Baade LE, Fenton WS, Gold JM, et al. The MATRICS Consensus Cognitive Battery, part 2: Co-norming and standardization. Am. J. Psychiatry. 2008; 165: 214-20.

46. Rodríguez-Jiménez R, Bagney A, García-Navarro C, Aparicio AI, López-Antón R, Moreno-Ortega M, et al. The MATRICS consensus cognitive battery (MCCB): Co-norming and standardization in Spain. Schizophr. Res. 2012; 134: $279-84$.

47. Endicott J, Spitzer RL, Fleiss JL, Cohen J. The global assessment scale. A procedure for measuring overall severity of psychiatric disturbance. Arch Gen Psychiatry. 1976; 33: 766-71.

48. American Psychiatric Association. Diagnostic and Statistical Manual of Mental Disorders DSM-IV, 4th ed. Washington, DC: American Psychiatric Association. 1994.

49. First, M.B, Spitzer, RL, Gibbon, M, Williams, JBW. Structured Clinical Interview for DSM-IV Axis I Disorders-Patient Edition (SCID-I/P, Version 2.0). Biometrics Research Department, New York State Psychiatric Institute, New York. 1995 
50. American Psychiatric Association. Diagnostic and statistical manual of mental disorders (DSM-III-R), text revision. 3rd ed. Washington, DC: American Psychiatric Association. 1987.

51. Endicott J, Spitzer RL, Fleiss JL, Cohen J. The Global Assessment Scale. A procedure for measuring overall severity of psychiatric disturbance. Arch Gen Psychiatry. 1976; 33: 766-71.

52. American Psychiatric Association. DSM-IV-TR Diagnostic and statistical manual of mental disorders (DSMIV-TR), text revision. 4th ed. Washington, DC: American Psychiatric Association. 2000.

53. Goldman HH, Skodol AE, Lave TR. Revising axis V for DSM-IV: A review of measures of social functioning. Am J Psychiatry. 1992; 149: 1148-56.

54. Loevdahl H, Friis S. Routine evaluation of mental health: Reliable information or worthless "guesstimates"? Acta Psychiatr Scand. 1996; 93: 125-8.

55. Pedersen G, Karterud S. The symptom and function dimensions of the Global Assessment of Functioning (GAF) scale. Compr Psychiatry. 2012; 53: 292-8.

56. Green MF, Nuechterlein KH, Kern RS, Baade LE, Fenton WS, Gold JM, et al. Functional co-primary measures for clinical trials in schizophrenia: Results from the MATRICS Psychometric and Standardization Study. Am J Psychiatry. 2008; 165: 221-8.

57. Karilampi U, Helldin L, Archer T. Cognition and global assessment of functioning in male and female outpatients with schizophrenia spectrum disorders. J Nerv Ment Dis. 2011; 199: 445-8.

58. Dickinson D, Ramsey ME, Gold JM. Overlooking the obvious: A meta-analytic comparison of digit symbol coding tasks and other cognitive measures in schizophrenia. Arch Gen Psychiatry. 2007; 64: 532-42.

59. Green MF, Nuechterlein KH, Gold JM, Barch DM, Cohen J, Essock S, et al. Approaching a consensus cognitive battery for clinical trials in schizophrenia: The NIMH MATRICS conference toselect cognitive domains and test criteria. Biol Psychiatry. 2004; 56: 301-7.

60. Ojeda N, Peña J, Sanchez P, Elizagarate E, Ezcurra J. Processing speed mediates the relationship between verbal memory, verbal fluency, and functional outcome in chronic schizophrenia. Schizophr Res. 2008; 101: 225-33.

61. Schaefer J, Giangrande E, Weinberger DR, Dickinson D. The global cognitive impairment in schizophrenia: Consistent over decades and around the world. Schizophr Res. 2013; 150: 42-50.

62. Niendam TA, Bearden CE, Zinberg J, Johnson JK, O'Brien M, Cannon TD. The course of neurocognition and social functioning in individuals at ultra high risk for psychosis. Schizophr Bull. 2007; 33: 772-81.

63. Jahshan C, Heaton RK, Golshan S, Cadenhead KS. Course of neurocognitive deficits in the prodrome and first episode of schizophrenia. Neuropsychology. 2010; 24: 109-20.

64. González-Blanch C, Crespo-Facorro B, ÁlvarezJiménez M, Rodríguez-Sánchez JM, Pelayo-Terán JM, Pérez-Iglesias R, et al. Cognitive dimensions in first-episode schizophrenia spectrum disorders. J Psychiatr Res. 2007; 41: 968-77.

65. Appels MC, Sitskoorn MM, Westers P, Lems E, Kahn RS. Cognitive dysfunctions in parents of schizophrenic patients parallel the deficits found in patients. Schizophr Res. 2003; 63: 285-93.

66. Wang Q, Chan R, Sun J, Yao J, Deng W, Sun X, et al. Reaction time of the Continuous Performance Test is an endophenotypic marker for schizophrenia: A study of firstepisode neuroleptic-naive schizophrenia, their non-psychotic first-degree relatives and healthy population controls. Schizophr Res. 2007; 89: 293-8.

67. Milev P, Ho BC, Arndt S, Andreasen NC. Predictive values of neurocognition and negative symptoms on functional outcome in schizophrenia: A longitudinal first-episode study with 7-year follow-up. Am J Psychiatry. 2005; 162: 495-506

68. Dickerson F, Boronow JJ, Ringel N, Parente F. Social functioning and neurocognitive deficits in outpatients with schizophrenia: A 2-year follow-up. Schizophr Res. 1999; 37 : 13-20.

69. Revheim N, Schechter I, Kim D, Silipo G, Allingham B, Butler P, et al. Neurocognitive and symptom correlates of daily problem-solving skills in schizophrenia. Schizophr Res. 2006; 83: 237-245.

70. Gold JM, Goldberg RW, McNary SW, Dixon LB, Lehman AF. Cognitive correlates of job tenure among patients with severe mental illness. Am J Psychiatry. 2002; 159: 1395-1402.

71. Harvey PD, Keefe RS, Patterson TL, Heaton RK, Bowie CR. Abbreviated neuropsychological assessment in schizophrenia: Prediction of different aspects of outcome. J Clin Exp Neuropsychol. 2009; 31: 462-71.

72. Brekke JS, Raine A, Ansel M, Lencz T, Bird L. Neuropsychological and psychophysiological correlates of psychosocial functioning in schizophrenia. Schizophr Bull. 1997; 23: 19-28.

73. Salthouse T.A. Speed mediation of adult age differences in cognition. Dev Psychol. 1993; 29: 722-38.

74. Hartman M, Steketee MC, Silva S, Lanning K, McCann H. Working memory and schizophrenia: Evidence for slowed encoding. Schizophr Res. 2003; 59: 99-113. 
75. Holthausen EA, Wiersma D, Sitskoorn MM, Dingemans PM, Schene AH, van den Bosch RJ. Long-termmemory deficits in schizophrenia: Primary or secondary dysfunction? Neuropsychology. 2003; 17: 539-47.

76. Brebion G, David AS, Bressan RA, Pilowsky LS. Processing speed: A strong predictor of verbal memory performance in schizophrenia. J Clin Exp Neuropsychol. 2006; 28 : 370-82.

77. Ojeda N, Peña J, Schretlen DJ, Sánchez P, Aretouli E, Elizagárate E, et al. Hierarchical structure of the cognitive processes in schizophrenia: The fundamental role of processing speed. Schizophr Res. 2012; 135: 72-8.

78. Rodríguez-Sánchez JM, Crespo-Facorro B, GonzálezBlanch C, Pérez-Iglesias R, Vázquez-Barquero JL. Cognitive dysfunction in first-episode psychosis: The processing speed hypothesis. Br J Psychiatry Suppl. 2007; 51: s107-10.
79. Mehta UM, Thirthalli J, Subbakrishna DK, Gangadhar BN, Eack SM, Keshavan MS. Social and neuro-cognition as distinct cognitive factors in schizophrenia: A systematic review. Schizophr Res. 2013; 148: 3-11.

80. Green MF, Leitman DI. Social cognition in schizophrenia. Schizophr Bull. 2008; 34: 670-2.

Corresponding author:

Dr. Roberto Rodriguez-Jimenez

Department of Psychiatry

Instituto de Investigación Hospital 12 de Octubre (i+12)

Avda. de Córdoba s/n

28041, Madrid

Spain

Telephone: 0034913908536

Fax: 913908538

E-mail: roberto.rodriguez.jimenez@gmail.com 